\title{
INTERACTS (INTErventional Radiotherapy ACtive Teaching School) consensus conference on sarcoma interventional radiotherapy (brachytherapy) endorsed by AIRO (Italian Association of Radiotherapy and Clinical Oncology)
}

\begin{abstract}
Luca Tagliaferri, MD, PhD', Andrea Vavassori, MD², Valentina Lancellotta, MD', Vitaliana De Sanctis, MD³,

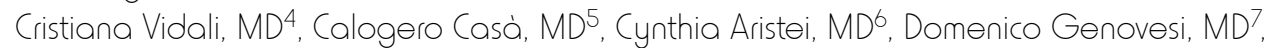
Barbara Alicja Jereczek-Fossa, MD2-8, Alessio Giuseppe Morganti, MD9. György Kovács MD, PhD5, Jose Luis Guinot, MD ${ }^{10}$, Agata Rembielak, MD, PhD"1, Daniela Greto, MD'2, Maria Antonietta Gambacorta, MD, PhD 15 Vincenzo Valentini, MD ${ }^{15}$, Vittorio Donato, MD ${ }^{13}$, Renzo Corvò, MD ${ }^{14}$, Stefano Maria Magrini, MD ${ }^{15}$, Lorenzo Livi, MD'2 and Consensus Conference Board*

IUOC Radioterapia Oncologica, Dipartimento di Diagnostica per Immagini, Radioterapia Oncologica ed Ematologia, Fondazione Policlinico Universitario A. Gemelli IRCCS, Rome, Italy, ${ }^{2}$ Department of Radiotherapy, IEO European Institute of Oncology IRCCS, Milan, Italy. 3Department of Radiation Oncology, Faculty of Medicina e Psicologia, Sant'Andrea Hospital, University of Rome "La Sapienza”, Rome, Italy, "Former Deputy Chair of Interventional Radiotherapy AIRO working Group - IntraOperative RadioTherapy, Trieste, Italy, "Università Cattolica del Sacro Cuore, Rome, Italy, 'Radiation Oncology Section, Department of Surgery and Biomedical Science, University of Perugia and Perugia General Hospital, Perugia, Italy, 'Department of Radiation Oncology, Santissima Annunziata Hospital, Gabriele D'Annunzio University of Chieti-Pescara, Chieti, Italy, ${ }^{8}$ Department of Oncology and Hemato-oncology. University of Milan, Milan, Italy, ${ }^{9}$ Department of Experimental, Diagnostic and Specialty Medicine - DIMES, University of Bologna, S. Orsola-Malpighi Hospital, Bologna, Italy, ${ }^{10 F o u n d a t i o n}$ Instituto Valenciano de Oncologia (I.V.O.), Valencia, Spain, "Department of Clinical Oncology, The Christie NHS Foundation Trust, Manchester and Division of Cancer Sciences, Faculty of Biology, Medicine and Health, University of Manchester, Manchester, United Kingdom, ${ }^{12}$ Radiotherapy Department, University of Florence, Florence, Italy, ${ }^{13}$ Radiation Oncology Department, Azienda Ospedaliera San CamilloForlanini, Roma, Italy, ${ }^{14}$ Radiation Oncology, IRCCS Ospedale Policlinico San Martino and Department of Health Science, University of Genoa, Italy, ${ }^{15}$ Radiation Oncology Department, Ospedali Civili Hospital and Brescia University, Brescia, Italy
\end{abstract}

*Consensus Conference Board: Rosa Autorino (radiation oncologist, Rome), Carmelo Caldarella (nuclear medicine physician, Rome), Annamaria Cerrotta (radiation oncologist, Milan), Antonino De Paoli (radiation oncologist, Aviano), Vitaliana De Sanctis (radiation oncologist, Rome), Nicola Dinapoli (radiation oncologist, Rome), Vittorio Donato (radiation oncologist, Rome), Martina Ferioli (radiation oncologist, Bologna), Vincenzo Fusco (radiation oncologist, Rionero in Vulture), Maria Antonietta Gambacorta (radiation oncologist, Rome), Domenico Genovesi (radiation oncologist, Chieti), Daniela Greto (radiation oncologist, Florence), Jose Luis Guinot (radiation oncologist, València), Roberto lezzi (interventional radiologist, Rome), Barbara Alicja Jereczek-Fossa (radiation oncologist, Milan), György Kovács (radiation oncologist, Rome and Lübeck), Valentina Lancellotta (radiation oncologist, Rome), Antonio Leone (radiologist, Rome), Giulio Maccauro (orthopedic surgeon, Rome), Stefano Maria Magrini (radiation oncologist, Brescia), Alessio Giuseppe Morganti (radiation oncologist, Bologna), Michela Quirino (medical oncologist, Rome), Agata Rembielak (clinical and radiation oncologist, Manchester), Umberto Ricardi (radiation oncologist, Turin), Vittoria Rufini (nuclear medicine physician, Rome), Giuseppe Sanguineti (radiation oncologist, Rome), Luca Tagliaferri (radiation oncologist, Rome), Andrea Vavassori (radiation oncologist, Milan), Cristiana Vidali (radiation oncologist, Trieste)

\begin{abstract}
Purpose: To report the results of INTERACTS (INTErventional Radiotherapy ACtive Teaching School) consensus conference on sarcoma interventional radiotherapy (brachytherapy).

Material and methods: An international board of multidisciplinary experts was invited to a consensus conference on the state-of-the-art of sarcoma interventional oncology during the $9^{\text {th }}$ Rome INTER-MEETING (INTERventional Radiotherapy Multidisciplinary Meeting), proposing 3 statements for each one speech. At the end of each lecture, the entire group of experts was invited to vote with an electronic device. The preliminary results were presented and
\end{abstract}

Address for correspondence: Valentina Lancellotta, MD, UOC Radioterapia Oncologica, Dipartimento di Diagnostica per immagini, Radioterapia Oncologica ed Ematologia, Fondazione Policlinico Universitario A. Gemelli IRCCS, Rome, Italy, 凶 e-mail: valentina.lancellotta@policlinicogemelli.it
Received: 11.05 .2020 Accepted: 09.07 .2020 Published: 21.08 .2020 
discussed at the end of the meeting, during a dedicated session. After the meeting, a survey was distributed within the consensus conference board to share and definitively vote the statements.

Results: All the invited authors of the consensus conference board completed the final survey. All the 38 statements received more than $70 \%$ of agreement, 31 statements (82\%) obtained an agreement of level higher or equal to $90 \%, 6$ statements $(15.8 \%)$ received an agreement level between $80 \%$ and $90 \%$, and 1 statement $(2.6 \%)$ had less than $80 \%$ of agreement.

Conclusions: The consensus conference demonstrated that interventional radiotherapy must be considered by a multidisciplinary management of patients affected by sarcoma.

J Contemp Brachytherapy 2020; 12, 4: 397-404 DOI: https://doi.org/10.5114/jcb.2020.98120

Key words: interventional radiotherapy, brachytherapy, soft-tissue sarcoma.

\section{Purpose}

Soft-tissue sarcoma (STS) is a rare heterogeneous family of diseases, encompassing a variety of different histological types and anatomic locations. In the USA alone, more than 13,000 new cases have been reported since 2018 [1]. Adequate surgical resection with the aim to achieve negative margins is the standard approach wherever feasible, but a close margin could be necessary to preserve uninvolved critical neurovascular structures [2]. In order to preserve structures and functions, conservative surgery has largely substituted an amputation for the treatment of extremity sarcomas.

Neoadjuvant treatments should be proposed to downstage large high-grade tumors, allowing for subsequent conservative surgery. Moreover, adjuvant treatments should be considered when pathological examination reveals risk factors for a relapse [3,4]. Nomograms are available to assess the risk of distant metastases and to predict the overall survival and disease-free survival rates $[5,6,7]$.

Brachytherapy, also called interventional radiotherapy (IRT), could be used as adjuvant monotherapy in selected cases. These include small to mid-sized $(<10 \mathrm{~cm})$ intermediate or high-grade tumors of the extremities or superficial trunk, excised with negative pathological margins, and small lesions with positive or uncertain margins and/or possible surgical field infection, independently from the grade of tumor. Other indications are limbs preservation and the need to maximize the functional outcome, if surgical resection would cause an unacceptable mutilation and/or if external beam radiation (EBRT) would lead to a major long-term sequela. Finally, IRT minimizes the need for daily sedation in pediatric patients, reduces the dose to normal tissues, and lowers the overall treatment time. Furthermore, IRT is an option when recurrence occurs in previously irradiated patients, if surgery is not feasible [8,9,10,11,12].

Before EBRT, IRT is used as a boost, and could be considered in cases of close/ positive margins $(<1 \mathrm{~mm}$ from inked margin) in high-grade STSs, for positive margins in low-grade STSs, or in not previously irradiated recurrent diseases $[13,14]$.

The latest guidelines from the European Society for Medical Oncology (ESMO) did not provide detailed assistance on radiotherapy (RT) technique, but indicated that IRT for the treatment of STSs is of unproven value and associated with high incidence of acute and late tox- icity [15]. This is likely due to low level of available data, with many relatively old papers published prior to the use of intensity-modulated and image-guided IRT.

Due to scientific evidence reported in literature, the contribution of IRT in the management of patients with STS is not clearly defined. Therefore, a consensus conference of Italian and international experts was arranged to share the best practice, and to develop a practical set of recommendations to guide clinical management of patients with STS.

The project was developed within the framework of brachytherapy, interventional radiotherapy, and intra-operative radiotherapy (IORT) study groups within the Italian Association of Radiotherapy and Clinical Oncology (Associazione Italiana di Radioterapia ed Oncologia Clinica - AIRO) and the INTErventional Radiotherapy ACtive Teaching School (INTERACTS), in order to define the role of IRT in interventional oncology with a multidisciplinary approach to the treatment of STSs.

\section{Material and methods}

A multidisciplinary board of twenty-nine experts in STSs management and IRT techniques was invited, according to their recognized clinical and research experience, to discuss the state-of-the-art of sarcoma interventional oncology during the $9^{\text {th }}$ Rome INTER-MEETING (INTERventional Radiotherapy Multidisciplinary Meeting) in 2018. There were twenty-three radiation oncologists, 2 nuclear medicine physicians, 1 medical oncologist, 1 orthopedic surgeon, 1 radiologist, and 1 interventional radiologist.

Before the meeting, each speaker provided one to three statements regarding the topic of presented lecture. A total of thirteen lectures were given during the meeting: 5 speeches were dedicated to the background, 3 focused on IRT and 2 on IORT, and 3 were related to multidisciplinary interventional management of patients affected by STS. At the end of each lecture, the entire group of experts was invited to vote with an electronic device. The preliminary results were presented and discussed at the end of the meeting, during a dedicated session.

After the meeting, to optimize scientific contribution and to allow maximum participation of the experts in the statement approval process, an independent coordinator (LL, not involved in the process) was nominated, and the statement vote was repeated using an online survey. Moreover, an independent expert in STS (DG) 
was involved in the consensus conference board. Every presentation was shared with the cohort of experts. The survey contained thirty-eight statements, organized in four sessions (1. Background, 2. IRT, 3. IORT, 4. Potential of multidisciplinary interventional oncology), and was hosted by SurveyMonkey (www.surveymonkey. com). The statements' vote was allowed from April $2^{\text {nd }}$, 2019 to May $5^{\text {th }}, 2019$. With participants' permission, the names of respondents were declared during the survey to avoid double completion of the survey itself, but they were blinded for subsequent data analysis performed by the authors. A master committee (MC) including AIRO and INTERACTS members at the time of event, discussed the survey results and approved this manuscript. The MC was formed by the independent coordinator (LL), the independent expert in STS field (DG), the chair, past chair, elected chair, deputy chairs, and secretariat of "BT, IRT, and IORT AIRO study group" (LT, CA, AV, VDS, CV, $\mathrm{VL}), 3$ members of AIRO scientific committee (RC - the chair of committee, DG, BJF), the school director, educational program director, and 3 international teachers of INTERACTS (VV, GK, AGM, AR, JLG), one member of AIRO committee, and the chair and elected chair of AIRO (MAG, SM, VD) at the time of event. The board defined the level of consensus according to the percentage of agreement to each statement as follow: a consensus level above $90 \%$ was defined as a full consensus, between $80 \%$ and $90 \%$ was considered as a moderate consensus, between $70 \%$ and $80 \%$ - a partial consensus, and no consensus was achieved for statements below $70 \%$ of agreement $[16,17]$.

\section{Results}

All the invited authors of the consensus conference board completed the survey. The results of the voting process are shown in Table 1 . All the 38 statements received more than $70 \%$ of agreement, 31 statements (82\%) received an agreement level higher or equal to $90 \%$, 6 statements $(15.8 \%)$ obtained an agreement level between $80 \%$ and $90 \%$, and 1 statement $(2.6 \%)$ had less than $80 \%$ of agreement.

Regarding radiological assessment, a $100 \%$ full consensus was reached in the statement on magnetic resonance imaging (MRI) as the optimal radiologic tool for local staging of all STS patients and in the statement on computed tomography (CT) as the optimal modality if MRI is contraindicated or in case of peculiar tumor location, such as chest, abdominal wall, or periscapular area. Radiography (moderate consensus with 83\%) was advisable before MRI in all STS cases as the main staging exam for STS. Instead, FDG-PET/CT was not regarded as mandatory $(93 \%)$ for preoperative work up, but potentially useful $(86 \%)$ after neo-adjuvant chemotherapy in predicting histopathologic and clinical response and survival, and in general, in predicting histopathologic grading, guiding targeted biopsy, in large necrotic lesions, and in prognostic stratification of predicting overall survival (OS) and progression-free survival (PFS) (90\%).

With regards to the therapeutic management, the commission agreed that, due to conflicting results from prospective studies and metanalysis, perioperative chemotherapy should not be considered as a standard treatment $(100 \%)$. Three courses of the epirubicin (Epi) and ifosfamide (Ifo) may be offered as an option for high-risk patients, preferably in the neoadjuvant setting and on the base of stage, histology, grade, depth, and tumor size. Histology-driven therapy failed to demonstrate any superiority (93\%) compared to Epi/Ifo schedule. Nomograms could be useful to personalize risk assessment and clinical decision-making (100\%). A complete consensus was achieved on conservative surgery as treatment of choice; although, surgery alone is often insufficient (100\%). The goal of biopsy is to obtain diagnostic tissue while minimizing morbidity, limiting potential tumor spread, and avoiding interference with future treatments (97\%). Only a partial consensus $(76 \%)$ was registered regarding the use of prosthesis reconstruction as a gold standard in the limb salvage surgery. During the discussion session, the scientific commission agreed with the statement only for tumors where a joint is not involved. Otherwise, other approaches should be considered, including neoadjuvant therapies or demolitive surgeries.

A considerable consensus was registered about the role of RT in general: $97 \%$ of the commission considered RT as a mandatory sequential treatment to surgery in most of STS extremities (both in pre- and post-operative settings). With the same consensus level, RT was considered a questionable treatment in retroperitoneal STS (if so, in the preoperative neoadjuvant setting). The statement on RT dose that should be kept around 60-65 Gy in post-operative treatment and $50 \mathrm{~Gy}$ in preoperative treatment, with both treatments provided with standard fractionation, met full consensus at $100 \%$.

A moderate agreement was registered for adjuvant IRT to treat small to mid-sized $(<10 \mathrm{~cm})$ high-grade tumors of extremities and trunk with negative surgical margins (83\%). Full 100\% consensus was found for IRT delivered to prevent surgical mutilation if EBRT would lead to major long-term sequelae, and/or administration of a lower then required dose. The statement on IRT used in combination with EBRT for close or positive margins in high-grade STSs and for positive margins in low-grade STSs was reached with $100 \%$ consensus. Similarly, the same $100 \%$ consensus was achieved in the statement that the total prescription dose of IRT boost should be ranging between 12 to 24 Gy (3-4.5 Gy per fraction) and depending on the EBRT dose (100\%).

With a moderate consensus $(83 \%)$, the panel considered IRT as more advantageous than EBRT to treat lesions of the trunk and extremity $<10 \mathrm{~cm}$ in size, and after complete surgical resection with negative margins and in histological high-grade cases.

Full $100 \%$ consensus was reached regarding IRT boost for dose escalation with a benefit, as compared with post-operative EBRT boost (93\%). The group agreed that IRT should be performed in centers of excellence, which operate within the neighboring radiation oncology departments as a network system (100\%).

The IRT alone was recognized as a procedure associated with a low-risk of acute and late toxicities (93\%). In particular, IRT alone was considered to be related with 
Table 1. Consensus conference results

\begin{tabular}{|c|c|c|}
\hline & $\begin{array}{l}\text { Consensus } \\
(\%)\end{array}$ & $\begin{array}{l}\text { Consensus } \\
\text { level }\end{array}$ \\
\hline \multicolumn{3}{|l|}{ Background } \\
\hline $\begin{array}{l}\text { Background: Radiography should be performed in all cases before MRI examination; ultrasound may } \\
\text { be used as the first line imaging modality only under certain circumstances. }\end{array}$ & 83 & Moderate \\
\hline $\begin{array}{l}\text { Background: MR imaging is generally considered the optimal radiologic tool in local staging of bone } \\
\text { and soft-tissue sarcomas. }\end{array}$ & 100 & Full \\
\hline $\begin{array}{l}\text { Background: CT is the optimal imaging modality to characterize soft-tissue mineralization and may } \\
\text { be preferred if MR imaging is contraindicated or for masses in various anatomic regions (periscapular } \\
\text { area, chest, or abdominal wall). }\end{array}$ & 100 & Full \\
\hline $\begin{array}{l}\text { Background: FDG-PET/CT is not mandatory in the pre-operative staging of patients with soft-tissue } \\
\text { sarcomas }\end{array}$ & 93 & Full \\
\hline $\begin{array}{l}\text { Background: After neo-adjuvant chemotherapy, FDG-PET/CT is potentially useful in predicting histo- } \\
\text { pathologic response and survival of patients with soft-tissue sarcomas. }\end{array}$ & 86 & Moderate \\
\hline $\begin{array}{l}\text { Background: Functional semi-quantitative parameters of FDG uptake degree and distribution within } \\
\text { the lesion may be useful in predicting histopathologic grading, guiding targeted biopsy (e.g. large } \\
\text { necrotic lesions), prognostic stratification (OS, PFS). }\end{array}$ & 90 & Moderate \\
\hline $\begin{array}{l}\text { Background: Due to conflicting results coming from prospective studies and metanalysis, perioper- } \\
\text { ative chemotherapy should not be considered a standard treatment option. It may be offered as an } \\
\text { alternative for high-risk patients, preferably in the neoadjuvant setting. }\end{array}$ & 100 & Full \\
\hline $\begin{array}{l}\text { Background: Risk should be carefully assessed, basing on a stage, histology, grade, depth, and size. } \\
\text { Nomograms can be useful to personalize risk assessment and clinical decision-making. }\end{array}$ & 100 & Full \\
\hline $\begin{array}{l}\text { Background: Three courses of Epi/Ifo should be considered as an option in the neoadjuvant setting, for } \\
\text { histology-driven therapy, which failed to demonstrate a superiority. }\end{array}$ & 93 & Full \\
\hline Background: Surgery is the treatment of choice of sarcoma, but often surgery alone is insufficient. & 100 & Full \\
\hline $\begin{array}{l}\text { Background: The goal of biopsy is to obtain diagnostic tissue while minimizing morbidity, limiting } \\
\text { potential tumor spread, and avoiding interference with future treatment. }\end{array}$ & 97 & Full \\
\hline Background: Prosthesis reconstruction is the gold standard in limb salvage surgery. & 76 & Partial \\
\hline $\begin{array}{l}\text { Background: Radiotherapy is a mandatory completion of surgical treatment in most STS cases of ex- } \\
\text { tremities. Both pre-operative and post-operative approaches provide similar DFS outcomes. }\end{array}$ & 97 & Full \\
\hline $\begin{array}{l}\text { Background: Radiotherapy is a questionable treatment in retroperitoneal STS: patients receiving radio- } \\
\text { therapy should be considered for preoperative treatment rather than post-operative. }\end{array}$ & 97 & Full \\
\hline $\begin{array}{l}\text { Background: Radiotherapy dose should be maintained as } 60-65 \text { Gy in post-operative and } 50 \text { Gy in } \\
\text { pre-operative treatment, with both given at a standard fractionation. }\end{array}$ & 100 & Full \\
\hline \multicolumn{3}{|l|}{ Interventional radiotherapy } \\
\hline $\begin{array}{l}\text { Interventional radiotherapy: Interventional radiotherapy boost after surgery can be used for small to } \\
\text { mid-sized }(<10 \mathrm{~cm}) \text { high-grade tumors of extremities and trunk with negative surgical margins. }\end{array}$ & 83 & Moderate \\
\hline $\begin{array}{l}\text { Interventional radiotherapy: Interventional radiotherapy is indicated if unlimited surgical resection } \\
\text { would lead to mutilation, and/or if external beam irradiation would lead to major long-term sequelae, } \\
\text { decreasing the EBRT required dose. }\end{array}$ & 100 & Full \\
\hline $\begin{array}{l}\text { Interventional radiotherapy: Interventional radiotherapy can be used in combination with external } \\
\text { beam radiotherapy for close or positive margins in high-grade STSS and for positive margins in low- } \\
\text { grade STSs. }\end{array}$ & 100 & Full \\
\hline $\begin{array}{l}\text { Interventional radiotherapy: Prescription dose of IRT-HDR boost should be in a range between } 3 \text { Gy } \\
\text { and } 4.5 \text { Gy, with a total of } 12-20 \text { Gy. Total dose (range, } 12-24 \text { Gy) should depend on EBRT dose. }\end{array}$ & 100 & Full \\
\hline $\begin{array}{l}\text { Interventional radiotherapy: For lesions of the trunk and extremity of }<10 \mathrm{~cm} \text { in size after complete } \\
\text { surgical resection with negative margins and high-grade tumors, fractionated IRT as monotherapy } \\
\text { could be more advantageous than EBRT. }\end{array}$ & 83 & Moderate \\
\hline $\begin{array}{l}\text { Interventional radiotherapy: Dose escalation with IRT boost could provide a benefit compared with } \\
\text { post-operative EBRT boost. }\end{array}$ & 93 & Full \\
\hline $\begin{array}{l}\text { Interventional radiotherapy: IRT should be performed in centers of excellence, which operate within } \\
\text { the neighboring radiotherapy departments in a network system. }\end{array}$ & 100 & Full \\
\hline
\end{tabular}


Table 1. Cont.

\begin{tabular}{|c|c|c|}
\hline & $\begin{array}{l}\text { Consensus } \\
(\%)\end{array}$ & $\begin{array}{l}\text { Consensus } \\
\text { level }\end{array}$ \\
\hline $\begin{array}{l}\text { Interventional radiotherapy: Brachytherapy alone is associated with a low-risk of acute and late tox- } \\
\text { icities. }\end{array}$ & 93 & Full \\
\hline Interventional radiotherapy: BT alone provides less toxicity, especially late toxicities, than EBRT and BT. & 93 & Full \\
\hline $\begin{array}{l}\text { Interventional radiotherapy: With appropriate planning, the risk of chronic toxicities, such as neurop- } \\
\text { athy and/or bone fracture is below } 10 \% \text {. }\end{array}$ & 97 & Full \\
\hline $\begin{array}{l}\text { Interventional radiotherapy: Although no randomized studies were available, suggestion can be made } \\
\text { about the reduction of radiation dose to adjacent OARs with HDR-BT. }\end{array}$ & 93 & Full \\
\hline $\begin{array}{l}\text { Interventional radiotherapy: Dosimetric constraints are the critical issues in reducing BT-related tox- } \\
\text { icities. }\end{array}$ & 97 & Full \\
\hline $\begin{array}{l}\text { Interventional radiotherapy: In specific situations, including recurrence disease and pediatric cancer, } \\
\text { BT should be considered as the first option. }\end{array}$ & 93 & Full \\
\hline \multicolumn{3}{|l|}{ Intraoperative electron radiation therapy } \\
\hline $\begin{array}{l}\text { Intraoperative electron radiation therapy: IOERT + surgery and pre- or post-operative EBRT are highly } \\
\text { effective in the treatment of STS of the extremities. High local control with less long-term toxicity and } \\
\text { more favorable functional outcomes are achievable, when compared to surgery and EBRT alone. }\end{array}$ & 90 & Moderate \\
\hline $\begin{array}{l}\text { Intraoperative electron radiation therapy: The association of preoperative EBRT, surgery, and IOERT } \\
\text { achieves high LC and limits side effects as compared to the approach with preoperative EBRT alone } \\
\text { in the treatment of RPS. This approach seems to be superior to the opposite combination, including } \\
\text { surgery, IOERT, and post-operative EBRT regarding local control and acute and late toxicity. }\end{array}$ & 97 & Full \\
\hline $\begin{array}{l}\text { Intraoperative electron radiation therapy: Recommended IOERT doses, combined with moderate dos- } \\
\text { es of EBRT ( } 45-50 \text { Gy), should be defined in the extent of surgical excision: } 10 \text { Gy with RO tumor resec- } \\
\text { tion margins, } 12.5 \text { Gy with R1 tumor resection margins, and } 15 \text { Gy with R2 tumor resection margins. }\end{array}$ & 100 & Full \\
\hline \multicolumn{3}{|l|}{ Potential of multidisciplinary interventional oncology } \\
\hline Tumor board: The management of STS should be carried out by a dedicated multidisciplinary team. & 100 & Full \\
\hline $\begin{array}{l}\text { ECT: Bleomycin is the better cytotoxic agent with electroporation to treat multiple skin lesions of vari- } \\
\text { ous histologies, including sarcomas. }\end{array}$ & 93 & Full \\
\hline $\begin{array}{l}\text { ECT: Electrochemotherapy can be used in a palliative setting in patients with soft-tissue sarcomas } \\
\text { metastases, unresponsive to chemo- or radio-therapy. }\end{array}$ & 97 & Full \\
\hline $\begin{array}{l}\text { ECT: Electrochemotherapy provides a symptomatic relief in skin metastasis from soft-tissue sarcomas; } \\
\text { the smaller the lesion, the better the response. }\end{array}$ & 93 & Full \\
\hline $\begin{array}{l}\text { Interventional radiology: Image-guided therapies for metastatic sarcoma, such as percutaneous ab- } \\
\text { lation and arterial embolization, may be alternatives or additions to surgery or radiation therapy in } \\
\text { patients with solitary or oligometastatic disease. }\end{array}$ & 97 & Full \\
\hline $\begin{array}{l}\text { Interventional radiology: Preoperative embolization of primary or metastatic soft-tissue tumors of the } \\
\text { extremities allows to reduce the risk of bleeding during and after surgery for hypovascularized tumors. }\end{array}$ & 100 & Full \\
\hline $\begin{array}{l}\text { Interventional radiology: Interventional radiology can also provide efficient and rapid pain palliation as } \\
\text { well as bone reconstruction, with the use of cementoplasty and percutaneous ablation/cryoablation. }\end{array}$ & 100 & Full \\
\hline
\end{tabular}

less toxicity (especially late) than EBRT plus IRT (93\%); the commission agreed that, with appropriate planning, the risk of chronic toxicities, such as neuropathy and/or bone fracture, are below 10\% (97\%). Expert opinions indicated that the reduction of radiation dose to adjacent OARs with IRT (93\%) and the dosimetric constraints were the critical issues in reducing IRT-related toxicities $(97 \%)$. Finally, in specific situations, such as recurrent disease and in pediatric patients, IRT should be considered as a first option $(93 \%)$.

With a good consensus, it was reported that IORT plus surgery and pre- or post-operative EBRT are very effective in the treatment of STS of the extremities, with high local control (LC) with less long-term toxicity and more favorable functional outcomes achievable when compared to surgery and EBRT alone (90\%). The association of preoperative EBRT, surgery, and IORT achieved high LC with limited side effects, as compared with an approach using preoperative EBRT alone in the treatment of retroperitoneal sarcomas. This approach seems to be superior to the sequence including surgery, IORT, and post-operative EBRT with regards to local control and acute and late toxicity (97\%). With a full consensus, the panel of experts recommended the following IORT dose when combined with EBRT total doses of 45-50 Gy, depending on the extent of surgical excision: $10 \mathrm{~Gy}$ in R0 tumor resection, 12.5 Gy in R1 tumor, and 15 Gy in R2 tumor resection $(100 \%)$.

All the experts agreed with the need of a dedicated multidisciplinary team to manage STSs $(100 \%)$. 
Regarding other interventional oncology treatments, where the available scientific evidence still places them only in a palliative/systemic disease setting, the consensus board specified that electrochemotherapy (ECT) may be recommended in a palliative setting in patients with metastases unresponsive to chemotherapy or RT (97\%). ECT provides a symptomatic relief in skin metastasis and the smaller the lesion, the better the response (93\%). Bleomycin was recognized as the most efficient cytotoxic agent with electroporation, in order to treat multiple skin lesions of various histopathologies, including sarcomas (93\%). In a palliative/ systemic disease setting, a full consensus was also recorded on image-guided therapies for metastatic sarcoma, such as percutaneous ablation and arterial embolization, which could be used as alternatives, and/or in substitution or in association with surgery or RT in patients with solitary or oligometastatic disease $(97 \%)$. With a full consensus, it was finally recognized that pre-operative embolization of primary or metastatic STS of the extremities permit to reduce the risk of bleeding during and after the surgery for hyper-vascularized tumors $(100 \%)$. Interventional radiology can also provide efficient and rapid pain relief as well as bone reconstruction, with the use of cementoplasty and percutaneous ablation/cryoablation $(100 \%)$.

\section{Discussion}

Soft-tissue sarcoma is a rare heterogeneous family of diseases with a multitude of pathologies and several anatomic locations [1]. Although amputation could still be an obligatory option for selected cases, limb-sparing surgery (LSS) represents the standard of care, using different reconstruction techniques to maintain member's functionality [2]. However, patients with poor prognostic factors, who undergo surgery could have a high-risk of local relapse within the first 5 years following the intervention $[18,19,20,21,22]$. Associated with LSS, EBRT achieves similar local control than amputation $[23,24,25,26,27,28]$. However, it is unclear whether the administration of EBRT is beneficial before or after surgery [29]. Adjuvant and neoadjuvant EBRT are comparable in terms of efficacy, with the latter associated with higher rate of acute toxicity and wound complications, but lower incidence of late toxicities and a potential of tumor downsizing when required for increasing the outcomes of subsequent limb-sparing surgery [30,31]. Different RT techniques, such as IRT or IORT, could be used with less toxicity and similar outcomes to EBRT, but they are performed in very few centers with an expertise in the field, especially in STS $[32,33,34,35,36]$.

Despite the data from the literature, the contribution of IRT (and generally of interventional oncology) to treat STS patients is not clearly defined $[15,35]$.

It was reported that adjuvant chemotherapy improves the survival of selected patients with STS but due to conflicting results from prospective studies and metanalysis, chemotherapy should not be considered as a standard treatment. It may be offered as an option for high-risk patients, preferably in the neoadjuvant setting $[37,38,39]$.

According to the level of evidences in scientific literature, other interventional oncology modalities, e.g. ECT and interventional radiology, should be considered for selected cases, particularly in palliative/systemic setting. In palliative setting, ECT could be used in patients with soft-tissue sarcomas metastases unresponsive to chemotherapy or RT providing a symptomatic relief in skin metastasis from STS $[40,41]$. Also, interventional radiology with percutaneous ablation and arterial embolization, may be alternatives or can be added to surgery or RT in patients with solitary or oligometastatic disease $[42,43,44]$. Each case should be discussed in the context of a specialized multidisciplinary team at diagnosis to establish the most appropriate therapeutic approach, maximizing the efficiency of the procedures, and shortening the time between interventions. Indeed, the presence of a dedicated tumor board was associated with an improvement of about $5 \%$ in the 2-year disease-free survival, and its absence was defined as a new poor-prognostic factor [45]. Moreover, the integration of a well-standardized data collection systems (large databases) could help to better analyze the outcomes in homogenous and also in non-homogenous series using several treatments, resulting useful in the comparison between different therapies $[46,47,48,49,50]$. The implementation of educational programs in this field could be useful to improve the therapeutic possibilities [34,36,51,52]. Due to lack of published data, consensus meetings as the one presented here, constitute an excellent opportunity to establish experts' opinion with the aim to provide the best diagnostic and therapeutic approaches in patients with STS [16].

\section{Conclusions}

This paper confirms that IRT is a treatment of sarcomas that needs to be considered with a multidisciplinary management of such patients. Therefore, we understand that our paper as a valuable experts' contribution highlighting the role of interventional oncology in STSs management. Further studies, with large database of patients, are required to achieve a stronger level of evidence.

\section{Acknowledgments}

The Authors would like to acknowledge the scientific committee of the AIRO for the critical revision of the paper.

\section{Disclosure}

The authors report no conflict of interest.

\section{References}

1. Siegel RL, Miller KD, Jemal A. Cancer statistics, 2018. CA Cancer J Clin 2018; 68: 7-30.

2. NCCN Clinical Practice Guidelines in Oncology (NCCN Guidelines $\left.{ }^{\circledR}\right)$ Soft Tissue Sarcoma Version 6.2019 - February 10, 2020. www.NCCN.org.

3. O'Sullivan B, Davis AM, Turcotte R et al. Preoperative versus postoperative radiotherapy in soft-tissue sarcoma of the limbs: a randomised trial. Lancet 2002; 359: 2235-2241.

4. Kandel R, Coakley N, Werier J et al. Surgical margins and handling of soft-tissue sarcoma in extremities: a clinical practice guideline. Curr Oncol 2013; 20: e247-254. 
5. Callegaro D, Miceli R, Bonvalot S et al. Development and external validation of two nomograms to predict overall survival and occurrence of distant metastases in adults after surgical resection of localised soft-tissue sarcomas of the extremities: a retrospective analysis. Lancet Oncol 2016; 17: 671-680.

6. Gronchi A, Miceli R, Shurell E et al. Outcome prediction in primary resected retroperitoneal soft tissue sarcoma: histology-specific overall survival and disease-free survival nomograms built on major sarcoma center data sets. I Clin Oncol 2013; 31: 1649-1655.

7. Cahlon O, Brennan MF, Jia X et al. A postoperative nomogram for local recurrence risk in extremity soft tissue sarcomas after limb-sparing surgery without adjuvant radiation. Ann Surg 2012; 255: 343-347.

8. Naghavi AO, Fernandez DC, Mesko N et al. American Brachytherapy Society consensus statement for soft tissue sarcoma brachytherapy. Brachytherapy 2017; 16: 466-489.

9. Laskar S, Pilar A, Khanna N et al. Interstitial brachytherapy for pediatric soft tissue sarcoma: Evolving practice over three decades and long-term outcomes. Pediatr Blood Cancer 2018; 65: e27112.

10. Sanmamed N, Berlin A, Beiki-Ardakani A et al. Magnetic resonance imaging-guided brachytherapy re-irradiation for isolated local recurrence of soft tissue sarcoma. Cureus 2018 10: e2457.

11. Nori D, Shupak K, Shiu MH et al. Role of brachytherapy in recurrent extremity sarcoma in patients treated with prior surgery and irradiation. Int J Radiat Oncol 1991; 20: 1229-1233.

12. Jebsen N, Engellau J, Bruland ØS. Scandinavian Sarcoma Group SSG XXIV - recommendations for radiotherapy in bone- and soft tissue sarcoma. http://www.ssg-org.net/ wp-content/uploads/2011/05/SSG-RT-Guidelines-December-2015.pdf.

13. Martínez-Monge R, Cambeiro M, Moreno M et al. Interaction of 2-Gy equivalent dose and margin status in perioperative high-dose-rate brachytherapy. Int J Radiat Oncol 2011; 79: 1158-1163.

14. Petera J, Soumarová R, Růžičková J et al. Perioperative hyperfractionated high-dose rate brachytherapy for the treatment of soft tissue sarcomas: multicentric experience. Ann Surg Oncol 2010; 17: 206-210.

15. Casali PG, Abecassis N, Bauer $S$ et al. Soft tissue and visceral sarcomas: ESMO-EURACAN Clinical Practice Guidelines for diagnosis, treatment and follow-up. Ann Oncol 2018; 29 (Suppl 4): iv51-iv67.

16. Jones J, Hunter D. Consensus methods for medical and health services research. BMJ 1995; 311: 376-380.

17. van de Velde CJH, Boelens PG, Borras JM et al. EURECCA colorectal: multidisciplinary management: European consensus conference colon \& rectum. Eur J Cancer 1990 2014; 50: 1.e1-1.e34.

18. Greto D, Loi M, Terziani F et al. A matched cohort study of radio-chemotherapy versus radiotherapy alone in soft tissue sarcoma patients. Radiol Med (Torino) 2019; 124: 301-308.

19. Muratori F, Frenos F, Bettini L et al. Liposarcoma: clinico-pathological analysis, prognostic factors and survival in a series of 307 patients treated at a single institution. J Orthop Sci Off J Jpn Orthop Assoc 2018; 23: 1038-1044.

20. Muratori F, Bettini L, Frenos F et al. Myxoid liposarcoma: prognostic factors and metastatic pattern in a series of 148 patients treated at a single institution. Int J Surg Oncol 2018; 2018: 8928706

21. Greto D, Loi M, Saieva C et al. Safety of concurrent adjuvant radiotherapy and chemotherapy for locally advanced soft tissue sarcoma. Tumori 2018; 104: 322-329.

22. Beltrami G, Rüdiger HA, Mela MM et al. Limb salvage surgery in combination with brachytherapy and external beam radiation for high-grade soft tissue sarcomas. Eur J Surg Oncol 2008; 34: 811-816

23. Greto D, Saieva C, Loi M et al. Patterns of care and survival in elderly patients with locally advanced soft tissue sarcoma. Am J Clin Oncol 2019; 42: 749-754.

24. Greto D, Saieva C, Loi M et al. Influence of age and subtype in outcome of operable liposarcoma. Radiol Med 2019; 124: 290-300.

25. Lancellotta V, Kovács G, Tagliaferri L et al. Age is not a limiting factor in interventional radiotherapy (brachytherapy) for patients with localized cancer. BioMed Res Int 2018; 2018: 2178469.

26. Mangoni M, Sottili M, Salvatore G et al. Enhancement of soft tissue sarcoma cell radiosensitivity by poly(ADP-ribose) polymerase-1 inhibitors. Radiat Res 2018; 190: 464-472.

27. Mangoni M, Sottili M, Salvatore G et al. Soft tissue sarcomas: new opportunity of treatment with PARP inhibitors? Radiol Med 2019; 124: 282-289.

28. Livi L, Shah N, Paiar F et al. Treatment of epithelioid sarcoma at the royal marsden hospital. Sarcoma 2003; 7: 149-152.

29. Wang D, Abrams RA. Radiotherapy for soft tissue sarcoma: 50 years of change and improvement. Am Soc Clin Oncol Educ Book 2014; 34: 244-251.

30. Greto D, Livi L, Saieva C et al. Neoadjuvant treatment of soft tissue sarcoma. Radiol Med 2014; 119: 195-200.

31. Gingrich AA, Bateni SB, Monjazeb AM et al. Neoadjuvant radiotherapy is associated with $\mathrm{R} 0$ resection and improved survival for patients with extremity soft tissue sarcoma undergoing surgery: A National Cancer Database Analysis. Ann Surg Oncol 2017; 24: 3252-3263.

32. Tagliaferri L, Pagliara MM, Boldrini L et al. INTERACTS (INTErventional Radiotherapy ACtive Teaching School) guidelines for quality assurance in choroidal melanoma interventional radiotherapy (brachytherapy) procedures. I Contemp Brachytherapy 2017; 9: 287-295.

33. Kovács G, Tagliaferri L, Valentini V. Is an Interventional Oncology Center an advantage in the service of cancer patients or in the education? The Gemelli Hospital and INTERACTS experience. J Contemp Brachytherapy 2017; 9: 497-498.

34. Tagliaferri L, Kovács G, Aristei C et al. Current state of interventional radiotherapy (brachytherapy) education in Italy: Results of the INTERACTS survey. J Contemp Brachytherapy 2019; 11: $48-53$

35. Kovacs G. Interventional oncology: should interventional radiotherapy (brachytherapy) be integrated into modern treatment procedures? Turk J Oncol 2019; 34 (Suppl 1): 16-22.

36. Morganti AG, Pasquarelli L, Deodato F et al. Videoconferencing to enhance the integration between clinical medicine and teaching: a feasibility study. Tumori 2008; 94: 822-829.

37. Chowdhary M, Chowdhary A, Sen N, et al. Does the addition of chemotherapy to neoadjuvant radiotherapy impact survival in high-risk extremity/trunk soft-tissue sarcoma? Cancer 2019; 125: 3801-3809.

38. Zaidi MY, Ethun CG, Tran TB et al. Assessing the role of neoadjuvant chemotherapy in primary high-risk truncal/ extremity soft tissue sarcomas: an analysis of the multi-institutional U.S. sarcoma collaborative. Ann Surg Oncol 2019; 26: 3542-3549.

39. Baldini EH, Le Cesne A, Trent JC. Neoadjuvant chemotherapy, concurrent chemoradiation, and adjuvant chemotherapy for high-risk extremity soft tissue sarcoma. Am Soc Clin Oncol Educ Book 2018; 38: 910-915.

40. Spugnini EP, Vincenzi B, Amadio B et al. Adjuvant electrochemotherapy with bleomycin and cisplatin combination for canine soft tissue sarcomas: A study of 30 cases. Open Vet J 2019; 9: 88-93.

41. Campana LG, Miklavčič D, Bertino G et al. Electrochemotherapy of superficial tumors - current status: basic princi- 
ples, operating procedures, shared indications, and emerging applications. Semin Oncol 2019; 46: 173-191.

42. Grilley-Olson JE, Webber NP, Demos DS et al. Multidisciplinary management of oligometastatic soft tissue sarcoma. Am Soc Clin Oncol Educ Book 2018; 38: 939-948.

43. Yu Y, Zhong Y, Wang J et al. Sarcomatoid hepatocellular carcinoma (SHC): a case report. World J Surg Oncol 2017; 15: 219.

44. Chick JFB, Branach C, Majdalany BS et al. Prone transradial catheterization for combined single-session transarterial embolization and percutaneous posterior approach cryoablation of solid neoplasms. Cardiovasc Intervent Radiol 2017; 40: 1026-1032.

45. Blay JY, Soibinet $P$, Penel $N$ et al. Improved survival using specialized multidisciplinary board in sarcoma patients. Ann Oncol 2017; 28: 2852-2859.

46. Tagliaferri L, Pagliara MM, Masciocchi C et al. Nomogram for predicting radiation maculopathy in patients treated with Ruthenium-106 plaque brachytherapy for uveal melanoma. J Contemp Brachytherapy 2017; 9: 540-547.

47. Meldolesi E, van Soest J, Alitto AR et al. VATE: VAlidation of high TEchnology based on large database analysis by learning machine. Colorectal Cancer 2014; 3: 435-450.

48. Tagliaferri L, Budrukkar A, Lenkowicz J et al. ENT COBRA ONTOLOGY: the covariates classification system proposed by the Head \& Neck and Skin GEC-ESTRO Working Group for interdisciplinary standardized data collection in head and neck patient cohorts treated with interventional radiotherapy (brachytherapy). J Contemp Brachytherapy 2018; 10: 260-266.

49. Damiani A, Masciocchi C, Boldrini L, et al. Preliminary data analysis in healthcare multicentric data mining: a privacy-preserving distributed approach. J E-Learn Knowledge Soc 2018; 14: 11.

50. Bussu F, Tagliaferri L, Mattiucci G et al. HDR interventional radiotherapy (brachytherapy) in the treatment of primary and recurrent head and neck malignancies. Head Neck 2019; 41: 1667-1675.

51. Autorino R, Vicenzi L, Tagliaferri L, et al. A national survey of AIRO (Italian Association of Radiation Oncology) brachytherapy (Interventional Radiotherapy) study group. J Contemp Brachytherapy 2018; 10: 254-259.

52. Tagliaferri L, Vavassori A, Lancellotta V, et al. Can brachytherapy be properly considered in the clinical practice? Trilogy project: The vision of the AIRO (Italian Association of Radiotherapy and Clinical Oncology) Interventional Radiotherapy study group. J Contemp Brachytherapy 2020; 12: 84-90. 